\title{
Reflection on the Transformation of Accounting Management Function under the Background of Big Data
}

\author{
Qi Wu \\ Xi'an University, NO1,Keji six Road, Yanta District of Xi'an, China,710065 \\ email :995570232@qq.com
}

Keywords: Al, Accounting functions, Transformation, Countermeasure

\begin{abstract}
The emergence of big data and artificial intelligence has changed the traditional accounting working environment and greatly improved the efficiency of accounting work. Big data and artificial intelligence influence the transformation of accounting functions from traditional accounting to management, and promote the further transformation of corporate financial work to the functions of supervision, analysis, prediction and decision-making. Therefore, we must attach importance to the transformation of accounting function, pay more attention to the theoretical research and application of the transformation of accounting management function. Through the analysis of the opportunity and dilemma of accounting function transformation, this paper puts forward the corresponding measures to better carry out the transformation and development of accounting function.
\end{abstract}

\section{大数据背景下会计管理职能转型思考 \\ 吴琦 \\ 西安文理学院经济管理学院, 雁塔, 西安, 陕西, 中国 \\ email :995570232@qq.com*}

关键词：人工智能；会计职能；转型；对策

中文摘要. 大数据和人工智能的出现改变了传统的会计工作环境, 极大的提高了会计工作的效 率。大数据和人工智能影响着会计职能由传统的核算型向管理型转变, 促使企业财务工作进 一步转向监督、分析、预测、决策的职能。为此, 我们必须重视会计职能的转型, 更加重视 会计的管理职能转型的理论研究和应用。本文通过对会计职能转型机遇与困境并存局面的分 析，提出了相应的措施，以期更好的进行会计职能的转型发展。

\section{1.研究背景及意义}

大数据和人工智能时代的信息技术革命比过去历次技术革命都要来的更加深刻, 对社会 带来的冲击将是空前的, 是技术革命的又一里程碑。传统的重复性较强的职业将被机器智能 所代替。会计行业也面临着前所未有的机遇与挑战: 传统的会计核算职能已经无法适应当前 的时代背景, 会计职能必须从重核算转向重管理。2016 年 3 月德勤与 Kira Systems 联手, 正 式将人工智能引入财务工作中, 使财务管理迈入了一个全新的时代。德勤智能机器人在录入 信息、合并数据、汇总统计、识别财务流程、业务逻辑判断等方面已显示出了特别明显的优 势。2017 年普华永道机器人已正式投入中化国际(控股)股份有限公司财务共享中心, 引进普 华永道智能机器人之后, 中化集团税务及财务工作效率明显提升, 并且在降低人力时间成本、 
提升工作质量等方面有明显的改善 ${ }^{[1]}$ 。威尔士特许会计师协会 (ICAEW) 安德鲁.拉特克利夫 认为“在数字化时代, 会计人必须成为能确保数据安全, 以及软件正常运行方面的专家; 在拥 有了更多的实用数据和更可靠的历史数据，必须加强对风险的识别和分析，为企业提供战略 预测和未来规划 ${ }^{[2]}$ 。”财务职能机器人的出现和快速投入使用为会计信息的收集、处理、分析 提供了广阔的空间。

\section{2.人工智能背景下会计职能转型的意义}

随着计算机技术的发展使得大数据和智能时代悄然来到我们身边，也使会计职能在拥有 机遇的同时面临着一系列的挑战。潘上永(2016)提出我国企业在新时代的转型促进了会计工 作的转型, 从传统的价值反映到价值创造, 从单一的核算到参与企业决策，会计工作的内涵 和实质都发生了巨大的转变。会计的核算职能随着智能财务机器人的出现随之减弱, 而会计 的管理职能将进一步加强 ${ }^{[3]}$ 。智能财务机器人革命将成为即会计电算化之后会计发展史的又 一历程碑。

某餐饮集团，以前 200 家门店的盘点数据必须在每个月的 1 号完成录入、过账和差异分 推, 最快的成本会计完成一家门店操作也需要 40 分钟, 但自从引入德勤智能机器人-“小勤人” 之后, 5 分钟后就可以完成一家门店的转账, 15 分钟后被标识这家门店已完成盘点, 并在工 作日结束时会发出邮件告知任务结束，附件包含所有生成的凭证，这一举措大大节省了餐饮 集团财务共享中心的人力和时间。通过实施“小勤人”自动化，企业相对应地减少了门店向共 享服务中心提交审核的相关流程, 缩短了财务处理周期, 还可以及时发现账实不符等现象并 进行及时处理, 实现了门店的统一管理, 优化了财务处理流程, 更重要的是提高了整体财务 服务水平。

智能财务机器人替代了会计人员录入数据等一系列前期繁琐的工作，降低了数据出错的 概率，提高了会计信息的可靠性和精准性。同时，在智能化、大数据的背景下，使企业可以 实现数据信息价值利用的最大化，把握实时的数据共享所发挥的最大利用价值，形成竞争优 势，为企业战略决策提供强有力的支撑。

在我国步入智能化、大数据的背景下，企业财务工作必须适应时代，不断加强自身的完 善和改革，特别是会计职能，必须适应大数据和智能时代发展。从核算类型到管理类型，确 保会计职能更加完善、系统, 力求发挥现代会计促进、约束、引导、调整等方面的职能和作 用。为适应新技术的到来, 企业必须更加重视会计职能的转型, 更加重视会计的管理职能, 重视管理会计的理论研究和应用。如果企业仍然在会计核算领域, 那只会导致企业竞争力下 降。

\section{3.人工智能背景下会计职能的转型需突破的困境}

\section{1 技术落伍, 难以满足企业个性化, 安全性基本要求}

数据化和智能化是建立在互联网快速发展基础上的，在信息化时代下，企业的硬件设施 和购入的财务软件难以适应各个公司的特殊性, 并没有兼容的特性, 很难做到满足企业的个 性化需求。另外，企业在收集信息的时候，由于互联网本身就缺乏安全性，信息中含有大量 的个人或者组织的私密信息。怎样保障这些信息的安全性是企业面对的一个重大问题。大数 据和人工智能除了本身信息安全外，它们也对企业信息保护以及避免核心数据丢失、防盗、 防窃方面也提出了更高的要求。如果企业核心技术外泄，通过信息化时代信息的多种传播途 径，会使企业商业机密外漏，给企业带来巨大的损失。

\section{2 面对人工智能的冲击,会计人员转型的形势严峻}

在大数据和人工智能带来诸多发展机遇的同时，会计人员也应该清醒的看到新形势下面 
临的影响和冲击。2014 年《经济学人》杂志调查结果, 未来会计被 AI 代替的可能性位于所 有职位的前列。王加灿(2017)认为人工智能可以促进会计新模式的发展, 财务职能机器人的 出现和使用，必定将人工智能引入会计、税务、审计工作，帮助财务人员从日常的基础核算、 审计工作中解脱出来, 将会计人员的工作重心投入到数据分析、预测决策管理工作中 ${ }^{[4]}$ 。2016 年麦肯锡预测“未来将有 $86 \%$ 的会计工作被人工智能产品取代，包括记账人员、核算人员等。 尽管人工智能不断推动着会计信息系统的完善与进步，但无疑使财会人员面临着愈发严峻的 就业形势 ${ }^{[5]}$ 。”因此企业会计人员和会计职能的转型应当是我们急需完成的首要任务。

\section{3 缺乏相应的法律法规及理论, 难以适应数据智能时代会计职能的转型}

大数据和人工智能高效、精准、而又全面的数据和信息处理能力，为市场发展带来机遇。 经过数年的发展我国大数据发展逐渐步入黄金时期，而由于大数据的支持人工智能也渗入到 人们的生活。这就给我们国家的政策法规和会计准则规范提出了新的要求。我们国家关于数 据和智能的法律法规以及理论还是很欠缺的, 如何建立完善会计法规和理论体系使其更加的 标准化, 适应数据智能的发展趋势是我们的首要任务。国家政策, 教育机制, 企业自身三方 面需要建立一套针对数据智能的标准化体系。以应对在数据智能时代会计所面临的就业危机、 信息安全和规范管理问题，技术软件局限、理论知识贵乏等实际问题，推进数据智能产业的 发展，使传统会计职能向管理会计职能有一个良好的过渡。

\section{4.完善人工智能背景下会计职能转型的应对措施}

\section{1 创新技术水平，完善软件开发的协作配合}

人工智能系统的研究和开发需要了解基础程序开发的计算机人员和具备会计专业知识的 专业会计人员的合作。只有程序开发员和专业会计人员相互配合，相互补充、积极创新，才 能在人工智能的系统的研究开发、维护和升级中发挥协同作用，促进会计行业人工智能的积 极发展。会计工作的完成，仅仅依靠基于程序化和规则化的会计软件是不可能的，一些突发 的、需要职业判断的工作仍需会计人员根据经验和知识灵活应对。

\section{2 加快会计人员的转型, 应对人工智能的“冲击”}

\section{2 .1 提升会计人员的专业知识能力}

代贞容(2017)、黄柳苍(2017)提出会计人员应顺应智能科技的巨变，努力学习、掌握计算 机和人工智能的专业基础知识, 不断武装充实自己, 让自己成为一名能够胜任现代企业财务 管理的专业人员。如果在大数据智能时代我们还停留在传统会计处理方法上, 那么注定被时 代淘汰。所以, 所有在职的财会人员必须用好国家继续教育这一平台, 借以学习人工智能在 会计行业的应用。或是个人实践练习掌握计算机智能操作技术, 培养自己管理思维能力, 加 快由财务会计向管理会计转型的脚步。

\subsection{2 提升会计人员的管理决策能力}

随着国家近几年对于管理会计发展的鼓励，各会计主体尤其是企业对管理会计人才的需 求增加。然而, 目前人工智能还无法完全替代会计核算职能, 更无法取代会计管理职能, 因 为企业大量的日常会计工作中离不开会计人员的职业判断及道德标准判定。这种背景下就要 求广大会计人员应顺势而变, 及时转变自己的思维方式, 提升自己的管理、分析决策能力, 提高自身竞争力，做人工智能所不能替代的工作。

\subsection{3 增强计算机网络技术的学习和实践}

定期为会计人员进行全面、系统的财务软件培训。企业要经常组织财会人员学习相关软 件的应用与操作，以加强会计人员对数据智能网络下会计职能的运用。使会计人员在掌握智 能化网络的前提下,与传统会计职能更好的融合在一起，以使会计职能在数据化智能化下拥有 更好的完善。另外要对计算机系统和办公环境加强安全保护，完善会计人员信息、搭建防火 
墙等一系列措施，加强和预防智能化时代下会计信息的安全防范。

\section{3 完善会计相关法律法规和理论体系，做好转型的各种准备}

国家的宏观政策法规必须随着会计环境的变化和会计主要职能的改变, 而随时进行相关 调整完善，在大数据和人工智能背景下，国家宏观管理层面对现代会计的管理职能、财务智 能机器人等新事物和新概念都必须有一个全新的认识, 依此进行相关会计法规及准则的增加 和完备、并在相关法律和法规中加以准确定位。不管是现在还是未来, 大数据和人工智能及 互联网等技术都对会计职能产生着颠覆性的影响。要想充分的提高管理会计职能, 就必须加 强信息化技术的运用。

同时，还要提高财务信息的分析运用水平，针对企业的具体情况进行数据筛选，不可盲 目使用。此外还要不断提高数据的准确性，让信息化技术更好的服务于会计，企业管理。财 会人员也要加强学习, 不断提升自身专业素质及能力, 以期更好的服务于企业和社会。国家、 教育机制以及企业自身三者共同构成会计职能向管理型职能转变的激励体系, 共同作用于我 国会计行业及市场经济的发展，为它们打下坚实基础。

\section{References}

[1] Shangyong Pan, On the Transformation and Upgrade of Accounting under the New Technology and Its Future Development, Friends of Accounting, vol. 23:2016.

[2] Canjia Wang, Artificial Intelligence and Accounting Model Change, Financial Communications, vol.22:2017. 